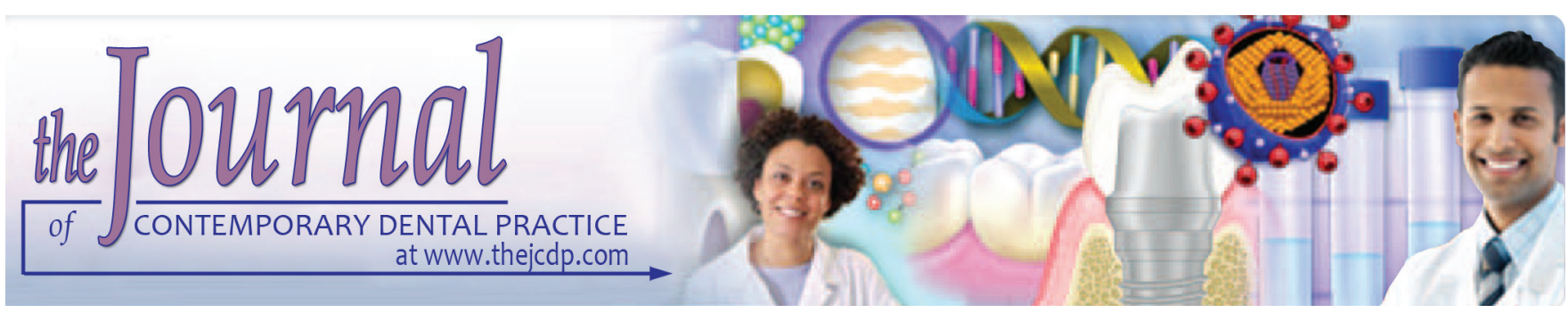

\title{
Comparative Evaluation of Antibacterial Effect of Dental Luting Cements on Streptococcus mutans and Lactobacillus acidophilus: An in vitro Study
}

${ }^{1}$ SMA Feroz, ${ }^{2}$ A Bhoyar, ${ }^{3} \mathrm{~S}$ Khan

\begin{abstract}
Introduction: This study aimed at evaluating and comparing the antibacterial activity of six types of dental luting cements on Streptococcus mutans and Lactobacillus acidophilus using the agar diffusion test (ADT) and the direct-contact test (DCT). The antibacterial activity in ADT was measured based on the diameter of the zone of inhibition formed, whereas in DCT the density of the bacterial suspension was measured. The lower the density of the suspension, the more antibacterial activity the cement possesses.

Materials and methods: Agar diffusion test was carried out on the bacteria. After an incubation period of 24 hours, the plates were checked for the presence of zone of inhibition. In DCT the cement was mixed and applied. Once the cement was set, bacterial suspension and brain-heart infusion medium was poured and incubated for 24 hours. After 24 hours, the plate was placed in the enzyme-linked immunosorbent assay plate reader, which measured the optical density of the fluid. The first set of data was recorded approximately 1 hour after incubation. Overall, three sets of data were recorded. Additional experiments were performed on set test materials that were allowed to age for 24 hours, 1 week, 1, 3, and 6 months.
\end{abstract}

Results: When using ADT only two cements zinc oxide eugenol (ZOE) and zinc polycarboxylate (ZPC) cement showed antibacterial activity against the test organisms. When using DCT, all cements showed some amount of antibacterial activity. Zinc oxide eugenol and ZPC cement showed highest amount of antibacterial activity against $S$. mutans and $L$. acidophilus respectively.

\footnotetext{
${ }^{1}$ Department of Prosthetic Dental Sciences, College of Dentistry Jazan University, Jazan, Kingdom of Saudi Arabia

${ }^{2}$ Department of Prosthodontics, Crown \& Bridge, People's College of Dental Sciences \& Research Centre, Bhopal, Madhya Pradesh, India

${ }^{3}$ Department of Maxillofacial Surgery and Diagnostic Sciences College of Dentistry, Jazan University, Jazan, Kingdom of Saudi Arabia

Corresponding Author: SMA Feroz, Department of Prosthetic Dental Sciences, College of Dentistry, Jazan University, Jazan Kingdom of Saudi Arabia, Phone: +966562793440, e-mail: feroz77777@gmail.com
}

Conclusion: Within the limitations of study, ZOE cement and ZPC cement were most effective against the tested microorganisms followed by the newer resin cement. The glass ionomer cement was the weakest of all.

Clinical significance: Patients with high caries index can be treated more effectively using the abovementioned cements.

Keywords: Agar diffusion test, Dental luting cements, Enzyme-linked immunosorbent assay, Zinc oxide eugenol, Zinc polycarboxylate.

How to cite this article: Feroz SMA, Bhoyar A, Khan S. Comparative Evaluation of Antibacterial Effect of Dental Luting Cements on Streptococcus mutans and Lactobacillus acidophilus: An in vitro Study. J Contemp Dent Pract 2016;17(12):973-977.

Source of support: Nil

Conflict of interest: None

\section{INTRODUCTION}

Dental luting agents provide the link between a fixed prosthesis and the supporting prepared tooth structure. An ideal dental cement should (1) provide a durable bond between dissimilar material, (2) possess favorable compressive and tensile strengths, (3) have sufficient fracture toughness to prevent dislodgement as a result of interfacial or cohesive failures, (4) exhibit adequate film thickness and viscosity to ensure complete seating, (5) be resistant to disintegration in the oral cavity, and (6) be tissue compatible. ${ }^{1,2}$

Loss of crown retention was found to be the second leading cause of failure of traditional crowns and fixed partial dentures. Failure of fixed partial dentures is most frequently caused by caries, which is being implicated mainly by two most common bacteria, i.e., Streptococcus mutans and Lactobacillus acidophilus. ${ }^{3}$ Cariogenic bacteria efficiently degrade fermentable carbohydrates to acids, which can further result in demineralization of tooth tissue, dental crowns, bridges, inlays, onlays, or veneers. 
Dental cements have a strong proclivity for dissolution in the oral fluids, resulting in marginal leakage and a roughened surface that accumulates food debris and bacteria. Due to potential for leakage, cement with antibacterial properties may be a useful defense against bacterial migration. In the past, several investigators have studied the antimicrobial action of dental cements in vitro and has generally concluded that all the tested materials had some bacteriostatic effect. ${ }^{4}$

Antibacterial properties of dental materials were studied by many researchers and by different methods of testing. The most useful and popular one is the agar diffusion test (ADT). However, it is affected by magnitude of contact area between the agar and the material, rate of diffusion, and the power of inherited antibacterial. ${ }^{5}$ Another method of measuring the antibacterial activity by luting cements is by the direct contact test (DCT), which was originally described by Weiss et al and is based on the turbidometric determination of bacterial growth in 96-well microtiter plates. Direct contact test relies on direct and close contact between the test microorganism and the test material, independent of the diffusion properties. With respect to caries prevention at the margins of cemented restoration, the DCT simulates the clinical situation in which the cariogenic microorganisms are in contact with the cement and therefore may be more suitable for testing restorative materials and cements than ADT. ${ }^{6}$

The purpose of this present study was to assess and compare the incessant antibacterial activity of six luting cements, i.e., zinc oxide eugenol (ZOE), zinc phosphate (ZPHS), glass ionomer cement (GIC), zinc polycarboxylate (ZPC), resin-reinforced GIC (RGIC), resin luting cements against $S$. mutans and L. acidophilus using DCT and ADT.

\section{MATERIALS AND METHODS}

Antibacterial activity of six types of dental luting cements were evaluated and compared with an interval of 24 hours using ADT and DCT at an interval of 1 hour, 24 hour, 1 week, 1, 3 and 6 months. The brands, types, and suppliers of materials used in this study are given in Table 1.

A specimen of bacteria culture was taken from the sample of dental plaque for S. mutans and L. acidophilus and obtained bacteria were confirmed by carrying out reaction of catalysis, hemolysis, and gram paint method.

\section{Agar Diffusion Test (ADT)}

Once the morphological and biochemical tests confirmed the presence of microbes, ADT was carried out. Bacterium in question was swabbed uniformly over media plate. Prepared cement disks were then placed on the surface
Table 1: Cements tested in the study

\begin{tabular}{|c|c|c|}
\hline SI. no. & Cement & Brand \\
\hline 1 & $\begin{array}{l}\text { Zinc oxide eugenol } \\
\text { cement [ZOE] }\end{array}$ & $\begin{array}{l}\text { Eugenol dental grade and, } \\
\text { Prime Dental Products Pvt } \\
\text { Ltd, Mumbai, India }\end{array}$ \\
\hline 2 & $\begin{array}{l}\text { Zinc phosphate cement } \\
\text { [ZNPHS] }\end{array}$ & $\begin{array}{l}\text { ZinCem, Medicept UK Ltd, } \\
\text { UK }\end{array}$ \\
\hline 3 & $\begin{array}{l}\text { Zinc polycarboxylate } \\
\text { cement [ZPC] }\end{array}$ & $\begin{array}{l}\text { HY-Bond polycarboxylate } \\
\text { cement, Shofu Inc., Japan }\end{array}$ \\
\hline 4 & $\begin{array}{l}\text { Glass ionomer cement } \\
{[\mathrm{GIC}]}\end{array}$ & $\begin{array}{l}\text { Luting and Lining cement } \\
\text { Gold Label, GC Corp., Japan }\end{array}$ \\
\hline 5 & $\begin{array}{l}\text { Resin-modified glass } \\
\text { ionomer cement [RGIC] }\end{array}$ & $\begin{array}{l}\text { Rely X Luting, 3M ESPE } \\
\text { Dental Products, USA }\end{array}$ \\
\hline 6 & Resin cement [RESIN] & $\begin{array}{l}\text { C and B cement, Bisco Inc., } \\
\text { USA }\end{array}$ \\
\hline
\end{tabular}

of brain-heart infusion agar broth media and left for 1 hour to allow diffusion. A suspension of streptococcal and lactobacillus culture was made in sterilized water blanks and was spread on the surface of petriplates. The streptococcal and lactobacillus culture were incubated for 24 hours at $37^{\circ} \mathrm{C}$ under anaerobic conditions, after which the plates were observed for formation of zone of inhibition. Antibacterial effect of either cement was evaluated by measuring mean diameter $(\mathrm{mm})$ of complete inhibition zones of bacterial growth around the disks.

\section{Direct Contact Test (DCT)}

Direct contact test is based on the turbidometric determination of bacterial growth in 96-well microtiter plates. Kinetics of growth in each well was recorded at $630 \mathrm{~nm}$ at $37^{\circ} \mathrm{C}$, using an enzyme-linked immunosorbent assay (ELISA) reader (Thermo Fischer). Auto mixing prior to each reading ensured a homogeneous bacterial cell suspension.

A micro titer plate was kept horizontally, and the floor of wells was coated evenly with a measured amount of the cement. A thin coat was achieved by using a small flat-ended dental spatula. The material was allowed to set in compliance with the manufacturer's recommendation. $50 \mu \mathrm{L}$ bacterial suspension (approximately $10^{6}$ ) was placed on the test material along with $100 \mu \mathrm{L}$ of brainheart infusion broth. A positive control as prepared by placing $50 \mu \mathrm{L}$ bacterial suspension along with $100 \mu \mathrm{L}$ of brain-heart infusion broth in a separate well without the cement. After 24 hours the suspension was transferred to an adjacent empty well, and then the readings were taken with the help of ELISA plate reader and the changes in optical density of the suspension were compared. First set of data was recorded approximately 1 hour after incubation. In all, three sets of data were recorded, i.e., three samples of each cement were tested. Additional experiments were performed on set test materials that were allowed to age for 24 hours, 1 week, 1, 3, and 6 months. 


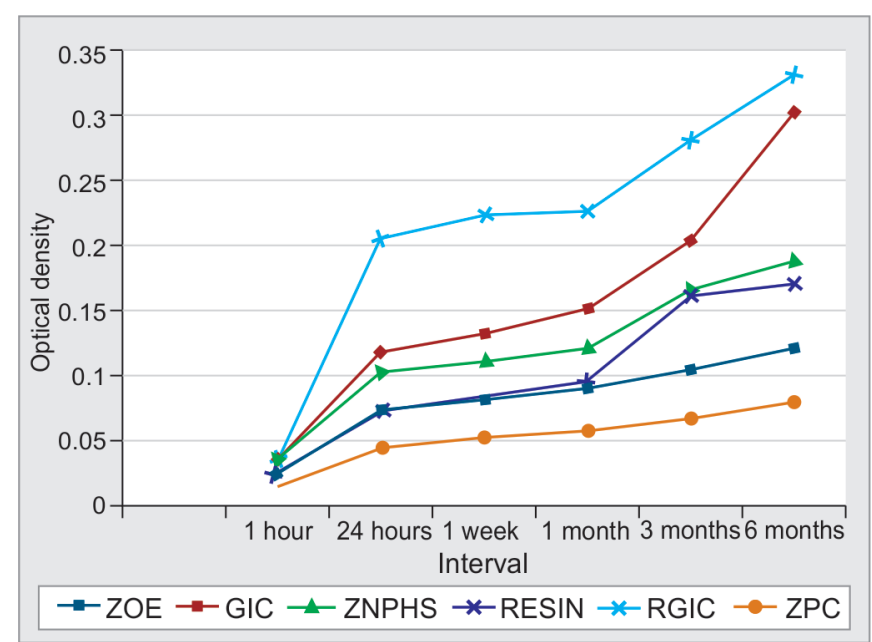

Graph 1: Line diagram showing the increase in density (decrease in antibacterial activity) of bacterial suspension of $L$. acidophilus against tested cements over a period of 6 months

\section{RESULTS}

\section{Agar Diffusion Test}

Out of six cements only two cements (ZOE and ZPC) gave positive antibacterial activity against $S$. mutans and L. acidophilus. Zinc oxide eugenol was found to be active against both strains of bacteria while ZPC was effective against $S$. mutans.

\section{Direct Contact Test}

When results for DCT were analyzed statistically using analysis of variance, it was evident that all six cements possessed significant amount of antibacterial activity at an interval of 1 hour, 24 hours, 1 week, 1, 3, and 6 months. And the difference obtained between control and cements was statistically significant $(p<0.05)$.

At the end of 6 months' period, ZOE cement shows the maximum amount of antibacterial activity against L. acidophilus (Graph 1) and S. mutans (Graph 2). Glass ionomer cement also showed antibacterial activity but when compared with the other five cements, it was found to be weakest of all with increase in density (decrease in antibacterial activity).

Mean values of density of bacterial suspension of $S$. mutans and L. acidophilus reveals that out of six luting cements, ZOE with mean lowest optical density possess high antibacterial property against both strains of bacteria followed by ZPC, resin luting cement, ZNPH, RGIC, and GIC respectively (Graph 3).

\section{DISCUSSION}

Sufficient control of dental plaque is the most important factor in caries prevention. Restoration margins can provide a potential pathway to leakage of cariogenic microorganisms present in the normal human flora. S. mutans

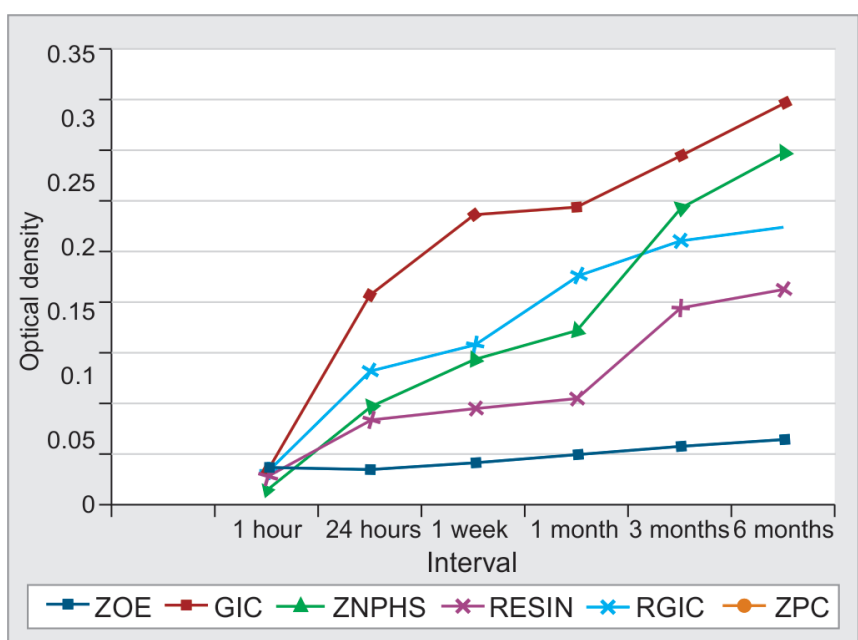

Graph 2: Line diagram showing the increase in density (decrease in antibacterial activity) of bacterial suspension of $S$. mutans against tested cements over a period of 6 months

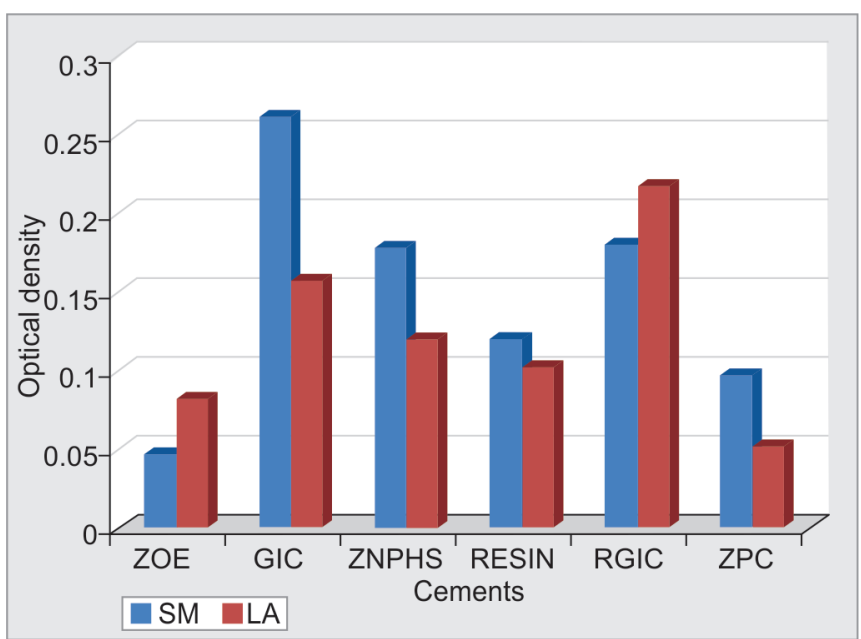

Graph 3: Bar diagram showing mean values of density of bacterial suspension of $S$. mutans and $L$. acidophilus against tested cements over a period of 6 months

and L. acidophilus are the most common caries-associated bacteria. Ideally, cements should possess antibacterial properties that will prevent bacteria-induced pulpal irritation, tooth sensitivity, and recurrent caries. Therefore, physically superior cements are important for caries prevention and longevity of cemented restorations. ${ }^{6}$

In this study the antibacterial activity of six luting cements was measured against two microorganisms $S$. mutans and L. acidophilus using the ADT and the DCT. The results varied between the two tests.

In ADT, ZOE showed the largest zone of inhibition measuring 13 and $12 \mathrm{~mm}$ against S. mutans and L. acidophilus respectively. The second cement which showed formation of a zone of inhibition was ZPC, which measured $11 \mathrm{~mm}$ against $S$. mutans but showed no activity against $L$. acidophilus. The remaining four cements did not show any antibacterial activity against the two test organisms. 
The lack of evidence for antibacterial activity for all of the test cements using ADT in the present study may be attributed to the characteristics of this test. Agar diffusion test is a popular test for antibacterial properties of restorative materials. However, it has several disadvantages. One primary disadvantage is that it depends on the solubility and diffusion properties of both the test material and media. It is possible that the antibacterial activity of the tested cements, which were not amply soluble, could not be detected by ADT. Dahl ${ }^{7}$ found high activity for polycarboxylate cement and ZPHS cement, whereas Schwartzman et $\mathrm{al}^{8}$ found low antibacterial activity for these cements.

For restorative materials and cements, which are expected to have low solubility and are less likely to diffuse, the ADT might not detect antibacterial properties. ${ }^{9}$ Furthermore, the results demonstrated that DCT, which relies on direct and close contact between the test microorganism and the test material, independent of the diffusion properties, may be more suitable for testing restorative materials and cements than ADT. With respect to caries prevention at the margins of cemented restorations, the DCT simulates the clinical situation in which the cariogenic microorganisms are in contact with the cement better than the ADT. However, it must be noted that the DCT experimental design employed is still far from the clinical situation in terms of oral environment, margin location, and surface area of cement exposed at restoration margins.

All cements showed some amount of antibacterial activity when tested with DCT. Zinc oxide eugenol cement was strongest against $S$. mutans (mean optical density $=0.048$ ) and 2 nd most powerful against L. acidophilus. Zinc polycarboxylate cement was the 2nd most and the most strong cement against $S$. mutans (mean optical density $=0.098$ ) and L. acidophilus (mean optical density $=0.053$ ) respectively. Zinc phosphate cement was the 4 th most powerful cement against $S$. mutans (mean optical density $=0.179$ ) and L. acidophilus (mean optical density $=0.120$ ).

Zinc-containing materials, such as ZPHS, ZPC, and $Z O E$ cements have been utilized for a number of years in clinical dentistry, due to their ability to release zinc ions that inhibit the growth of caries-related bacteria. ${ }^{10,11}$ The high antibacterial activity obtained for zinc containing cements in this study can be attributed to the property of zinc acting as an inhibitor of multiple activities in the bacterial cell, such as glycolysis, transmembrane proton translocation, and acid tolerance. Antibacterial action of zinc is similar to fluoride, but it works better in neutral $\mathrm{pH}$ (while the inhibitory potency of fluoride for glycolysis is very much greater at acid $\mathrm{pH}$ values). Zinc can also enhance proton permeability of bacterial cells membrane.
It reduces proton-extruding ATP-ase activity. Moreover, zinc acts to diminish ATP synthesis in glycolyzing cells because it can inhibit the glycolytic enzymes glyceraldehyde-3-phosphate dehydrogenases and pyruvate kinase, as well as the metabolism of phosphoenolpyruvate. ${ }^{12}$

Resin cement was the 3rd most powerful cement against $S$. mutans (mean optical density $=0.120$ ) and L. acidophilus (mean optical density $=0.104$ ). Resinreinforced GIC was the 5 th most powerful cement against S. mutans (mean optical density $=0.177$ ) and the weakest cement against $L$. acidophilus (mean optical density = $0.217)$. Fluoride is widely used as an anticariogenic material in many dental products. ${ }^{13-15}$ The antibacterial activity showed by resin-modified glass ionomer and resin cement can be attributed to the release of fluoride. Various mechanisms are involved in the anticariogenic effects of fluoride on the teeth, including the reduction of demineralization, the enhancement of remineralization, the interference of pellicle and plaque formation, and the inhibition of microbial growth and metabolism. The most important anticariogenic property of fluoride in luting cements is the effect on cariogenic oral bacteria, especially on S. mutans. Fluoride can inhibit many enzymes involved in bacteria metabolism, the inhibition of the glycolytic enzyme enolase and the proton-extruding ATP-ase; acid phosphatase, pyrophosphatase, peroxidase, and catalase may be affected by fluoride ions also. In such a way, fluoride inhibits production of bacterial acids and glucans, especially insoluble glucan produced by $S$. mutans. As insoluble glucans are important for virulence of mutans streptococci, the inhibitory actions of fluoride could significantly affect cariogenicity. ${ }^{16}$

The other action of fluoride ions leading to inhibition of glucans and acid production by cariogenic bacteria at low $\mathrm{pH}$ values involves its capacity to induce acidification and starvation stresses on the cell. Fluoride is acting in the form of protonated fluoride (HF) as a transmembrane proton carrier. It enhances proton permeability of cell membranes (to HF the cell is some 107 times more permeable than to $\mathrm{F}^{-}$). Proton-extruding ATP-ases are overloaded and disturbed to extrude proton because excreted proton gets back into the cell due to movements of HF. It causes absence of ATP and starvation of bacterial cell. Moreover, HF dissociates to the $\mathrm{F}^{-}$(enzyme poison) and $\mathrm{H}^{+}$, which acts to acidify the cytoplasm and inhibit glycolytic enzymes. Eventually, lowering $\mathrm{pH}$ compromises the energetic status of the cell by increasing re-entry of protons across the cell membrane. It increases the demand on ATP for acid-base regulation. ${ }^{17}$

The glass ionomer was the weakest cement against S. mutans (mean optical density $=0.260$ ) and 5 th most powerful cement against L. acidophilus (mean optical density $=0.157)$. Herrera et $\mathrm{al}^{18}$ studied the antibacterial 
activity of various restorative materials with cariogenic bacteria using the ADT. The authors found a wide range of antibacterial activity of different cements, while only $2 \%$ of the Ketac-Cem specimens showed positive antibacterial properties. Loyola-Rodriguez et $\mathrm{al}^{19}$ examined the factors involved in the antibacterial activity of various GICs on mutans streptococci. The authors found that GIC exhibits low antibacterial properties, which could be attributed to the low fluoride release of this cement. Another explanation could be the lack of zinc-oxide powder in its composition. It has been suggested that GICs containing zinc-oxide powder are more effective in microbial inhibition due to the direct effect of zinc-oxide powder and the cationic effect of the zinc. ${ }^{20}$

Within the limitations of study, ZOE cement and ZPC cement were most effective against the tested microorganisms followed by the newer resin cement. Patients with high caries index can be treated more effectively using abovementioned cements.

\section{REFERENCES}

1. Williams VD. Factors that affect the adhesion of composite to enamel. Gen Dent 1982 Nov-Dec;30(6):477-480.

2. Smith DC. Dental cements: current status and future prospects. Dent Clin North Am 1983 Oct;27(4):763-792.

3. Philip J. Lactobacillus acidophilus and dental caries. Am J Public Health 1938 Jun;28(6):759-761.

4. Schwartzman B, Caputo AA, Schein B. Antimicrobial action of dental cements. J Prosthet Dent 1980 Mar;43(3):309-312.

5. Hassan AK. Antibacterial activity of dental luting cement. J Minim Interv Dent 2009;2(4):220-222.

6. Lewinstein I, Matalon S, Slutzkey S, Weiss EI. Antibacterial properties of aged dental cements evaluated by directcontact and agar diffusion tests. J Prosthet Dent 2005 Apr;93(4):364-371.

7. Dahl BL. Antibacterial effect of two luting cements on prepared dentin in vitro and in vivo. Acta Odontol Scand 1978;36(6):363-369.
8. Schwartzman B, Caputo AA, Schein B. Antibacterial action of dental cements. J Prosthet Dent 1980 Mar;43(3):309-312.

9. Tobias RS. Antibacterial properties of dental restorative materials: a review. Int Endod J 1988 Mar;21(2):155-160.

10. Imazato S, Torii Y, Takatsuka T, Inoue K, Ebisu S. Bactericidal effect of dentin primer containing antibacterial monomer methacryloyloxydodecylpyridinium bromide (MDPB) against bacteria in human carious dentin. J Oral Rehabil 2001 Apr;28(4):314-319.

11. Boyd D, Li H, Tanner DA, Towler MR, Wall JG. The antibacterial effects of zinc ion migration from zinc-based glass polyalkenoate cements. J Mater Sci Mater Med 2006 Jun;17(6):489-494.

12. Phan T-N, Buckner T, Sheng J, Baldeck JD, Marquis RE. Physiologic actions of zinc related to inhibition of acid and alkali production by oral streptococci in suspensions and biofilms. Oral Microbiol Immunol 2004 Feb;19(1):31-38.

13. Bowden GH. Effects of fluoride on the microbial ecology of dental plaque. J Dent Res 1990 Feb;69:653-659.

14. Hamilton IR. Biochemical effects of fluoride on oral bacteria. J Dent Res 1990 Feb;69:660-667.

15. Tatevossian A. Fluoride in dental plaque and its effects. J Dent Res 1990 Feb;69:645-652.

16. Koo H, Sheng J, Nguyen PTM, Marquis RE. Co-operative inhibition by fluoride and zinc of glucosyl transferase production and polysaccharide synthesis by mutans streptococci in suspension cultures and biofilms. FEMS Microbiol Lett 2006 Jan;254(1):134-140.

17. Svensater G, Sjogreen B, Hamilton IR. Multiple stress responses in Streptococcus mutans and the induction of general and stress-specific proteins. Microbiology 2000 Jan;146(Pt 1): 107-117.

18. Herrera M, Castillo A, Bravo M, Liebana J, Carrion P. Antibacterial activity of resin adhesives, glass ionomer, and resin-modified glass ionomer cements and a compomer in contact with dentin caries samples. Oper Dent 2000 Jul-Aug; 25(4):265-269.

19. Loyola-Rodriguez JP, Garcia-Godoy F, Lindquist R. Growth inhibition of glass ionomer cements on mutans streptococci. Pediatr Dent 1994 Sep-Oct;16(5):346-349.

20. Scherer W, Lippman N, Kaim J. Antibacterial properties of glass-ionomer cements and other restorative materials. Oper Dent 1989 Spring;14(2):77-81. 